\title{
KAIRÓS: VALSAR COM A INFÂNCIA, NA ESCOLA, ATRAVÉS DA EXPERIÊNCIA FILOSÓFICA
}

\author{
Gustavo Tanus Martins ${ }^{1}$
}

A relação com as crianças é uma relação de alteridade. De estranheza. De mistério. De tremor. De perplexidade. De perturbação (SKLIAR, 2014, p.122).

\section{INTRODUÇÃO}

O percurso dos estudos sobre as crianças e as infâncias remete-nos a multiplicar as zonas conceituais para talhar esses conceitos em horizontes filosóficos que poderão, entre outras coisas, auxiliar a problematizar a univocidade da infância, e com isso, de uma vez por todas colocar em evidência a pluralidade desse conceito "infâncias". Enquanto não desobedecermos ${ }^{2}$ certos ditos da linguagem não se pode estar com as crianças, muito menos compreender a infância.

Colocar-se à altura das crianças não parece ser tarefa simples, provoca-nos Montaigne (1996). Para o filósofo, colocar-se à altura contempla dois sentidos: estar na mesma altura física da criança, ou seja, nos deslocarmos de uma posição mais alta e ficarmos à altura delas. Um segundo sentido, seria compreender essa criança em um movimento maior, que possa envolver empatia e alteridade, mas algumas questões nos provocam: quanto conseguimos fazer isso? Quanto conseguimos estar com as crianças? Habitar seu universo e perceber tal infância? Existe algum limite para essa aproximação?

As crianças de-moram, pois tudo está perto de uma suposta originalidade - pelo menos em sua vida - algo próximo àquilo que, talvez, possa ser compreendido como estado de paixão. A paixão é a fruição, ela é incontrolável. As crianças, assim como a paixão, agudizam-se no desejo incontornável de agir no mundo sem interdição. Se querem correr, correm, se desejam chorar, choram e assim, o estado de paixão não se conhece na interdição, a não ser quando pelo desejo de acabamento, quando aos poucos, a paixão é domada, tal como a criança civilizada. Mais uma vez pode-se relacionar com a paixão. Aquela sensação nova, aquele instante em que pode ser eterno para aquele que vive, mas rápido para quem está de fora, ou ainda ter a sensação de algo que passou rápido cronologicamente, mas foi de uma potência incrível, por sua intensidade. Surgem reflexos no corpo,

\footnotetext{
${ }^{1}$ Naturólogo, Pedagogo. Mestre em Educação. Doutorando em Educação, na linha de Filosofia da Educação (UFSC). gunaturologia@gmail.com

2 Ideia encontrada no livro Desobedecer a linguagem de Carlos Skliar.
} 
que se tornam involuntários: coração que acelera, mãos que transpiram, pernas que ficam bambas e “borboletas no estômago". Nesse sentido, paixão e infância transbordam, tal como um grito (KOHAN, 2009). É a nova descoberta, é a possibilidade de de-morar vivamente naquilo que é novo, na mão, no gesto, no outro. Pura afecção de encontrar-se no outro. Possibilidade dada que já é.

Para esse de-morar-se, podemos nos apoiar em Masschelein (2008) “A pedagogia pobre nos convida a sair para o mundo, a nos expormos; em outras palavras, a nos colocarmos numa "posição" fraca, desconfortável, e oferece meios e apoio para que façamos isso.” (p. 43) que ainda completa dizendo que a pedagogia pobre, generosa, é responsável por dar tempo e espaço, os quais tornam-se significativos para a experiência, ou seja, ela não está disposta a ser dona de qualquer conhecimento, ser vista como uma máxima a ser alcançada, ela não é controladora, nem mesmo supervisora, simplesmente "[...] convida a caminhar pelas estradas, a entrar no mundo, a copiar o texto, ou seja, a expor-se." (p. 43).

Então, o que restaria nesse caminhar? Resta duvidar, olhar com outros olhos, ou, até mesmo, desobedecer:

\begin{abstract}
A fala, a leitura e a escrita procedem e advêm de certo tipo de experiência de desobediência da linguagem. Se a linguagem não desobedecesse e se não fosse desobedecida não haveria filosofia, nem arte, nem silêncio, nem mundo, nem vida [...] A linguagem que desobedece e é desobedecida: colocar-nos fora de nós mesmos, nessa existência desoladora, nessa brecha sonora e silenciosa - que abre a possibilidade para a produção de um sentido (SKLIAR, 2014, p.17).
\end{abstract}

Aqui se trata de desobedecer, compreendendo a seriedade de lidar com um conceito. Não é algo feito por teimosia, ou de qualquer jeito. Desobedecer torna-se, portanto, uma possível forma de “ser" próximo da criança e desse momento apaixonado e apaixonante, que é a infância, dessa forma, talvez, possa-se estar à altura da criança e próximos de recordar-nos da infância. Um recordar para estar com. Esse deslocamento exigiria destituir-se de um excesso de autoritarismo que permitiria habitar a infância, mesmo estando em outra posição, vivendo a "adultez".

Na dobra desses deslocamentos, cabe destacar:

É preciso libertar a criança da "infância", quero dizer, dessa situação de controle estrito e, a pretexto de amadurecimento, dessa interiorização das coações e dos comportamentos embrutecedores, em relação aos adultos, que lhe são incutidos pela pedagogia [...] (SCHÉRER, 2009, p. 35). 
O que está sendo discutido aqui não é exclusivamente um conceito, ou definições do que significam crianças ou infâncias. É isso também, mas torna-se fundamental a ideia de (re) pensar aquilo que se discute ao longo de graduações em Pedagogia, que não apenas infância e o sujeito criança, mas ainda o que se entende e/ou acredita-se ser o papel da escola. Para tanto, cabe pensar: qual seria o real lugar da criança na educação?

Schérer (2009, p. 31), para auxiliar na busca por alguma resposta, diz que “[...] a criança é um ser utópico precisamente pelo fato de estar confinada nesse lugar escolhido para ela e que é um vazio, um não-lugar”. Quanto um professor, ou futuro professor, estaria distante dessa utopia?

[...] papel do professor não é menos utópico no sentido em que, por um lado, ele se coloca à distância, não deixando de pretender estar próximo, e, por outro, ele abandona, em atenção à criança, seu lugar entre os adultos, sem que por isso volte a ser criança, quer dizer, sem deixar de ser pedagogo. (SCHÉRER, 2009, p. 31).

Essa reflexão parece ser importante para mobilizar outras reflexões pensando na ideia de ser professor. Na educação, sobretudo, na educação das crianças, parece existir um lugar que pertence ao adulto, no qual este apresenta-se instalado, mas ao contrário, como nos apresenta Schérer, deve-se pensar em um lugar "vazio", ao invés de um lugar "preenchido", ocupado por um saber, por um conhecimento tido como verdadeiro.

Ter conhecimento científico parece ser fundamental, mas até que ponto? Até quando? Não se trata de exclusão daquilo que é científico, mas acreditamos ser possível colocar em xeque esse único elemento - conhecimento científico - para podermos compreender conceitos e, formas de ser e estar no mundo, tão complexos, a saber: criança e infância.

A tradição pedagógica ${ }^{3}$ nos faz buscar as respostas, o tempo todo, isso acaba prejudicando a abertura para outras possibilidades, para visitar novos horizontes e consequentemente (re) pensar um processo educacional e até mesmo formativo.

\footnotetext{
3 Concepção pedagogia tradicional, tem base a leitura feita por Saviani (2005) "[...] a expressão "concepção tradicional” subsume correntes pedagógicas que se formularam desde a Antiguidade, tendo em comum visão filosófica essencialista de homem e uma visão pedagógica centrada no educador (professor), no adulto, no intelecto, nos conteúdos cognitivos transmitidos pelo professor aos alunos, na disciplina, na memorização.” (p.31).

Texto: http://www.histedbr.fe.unicamp.br/navegando/artigos_pdf/Dermeval_Saviani_artigo.pdf Acesso em: 04 de setembro de 2017.
} 
Para podermos compreender melhor essa questão, voltamos a ressaltar esse "não lugar" apresentado para a criança. Pensemos, portanto, o conceito de "devir-criança", apresentado por Deleuze e retomado por Schérer (2009). Segundo Gilles Deleuze (1997, p. 193),

\begin{abstract}
Pensar o devir-criança, pensar a infância a partir dele, em sua esfera, é rejeitar o acervo de ideias, os pesados grilhões e disfarces impostos à infância pela tradição pedagógica e psicológica, bem como pelo universo psicanalítico com seus estágios, suas transferências, suas castrações, sua subordinação da infância à uma significação única, à verticalidade de uma única ereção.
\end{abstract}

Por um lado, pelo inacabamento da infância, existe a possibilidade desse "devir-criança". Entretanto, “[...] não existe devir-homem, o que significa que o homem não pode ser considerado num devir, limitando-se a ser [...]" (SCHÉRER, 2009, p. 207). Dessa forma, estaríamos, enquanto adultos (supostamente acabados), destituídos de um “devir". O devir-homem (adulto) não existe nem como substantivo (pensando em um estado), nem mesmo como verbo (pensando de forma ativa). Caberia aos adultos imaginar apenas um lugar, a própria infância e com isso, outros caminhos para a educação.

\footnotetext{
Voltar o olhar para si mesmo, repensar tudo o que nos foi pensado a partir da academia, a partir dos textos especializados, a partir dos discursos politicamente corretos, a partir das consciências acomodadas daqueles que se conhecem como parte da normalidade, do racional, do democrático, do verdadeiramente humano, é o que provoca a relação direta e aberta com aqueles que não fazem parte de todas essas certezas (SKLIAR, 2003, p.13).
}

Desorganiza-se aqui essa possibilidade única, o ideal da razão, do verdadeiro, do normal. Cria-se uma possibilidade outra. Rompe-se aquilo que parece ser a regra preestabelecida. Abre-se outra possibilidade.

\title{
POR UMA ESCOLA-OUTRA
}

“[...] educamos según el mito que podemos fabricar otros seres humanos que los que somos, seres mejores, más justos, más felices. ${ }^{4}$ " (KOHAN, 2009, p.31).

\footnotetext{
4 "Educamos segundo um mito que podemos fabricar outros seres humanos, seres melhores, mais justos, mais felizes". (Livre tradução nossa)
} 
Pensar a possibilidade de uma escola-OUTRA não é tarefa simples, mas algumas coisas devem estar claras para que a ideia possa ser compreendida. Para tanto tem-se como aporte Veiga e Fonseca (2012), quando nos falam de escola, referindo-se às questões de ensino e aprendizagem e ao currículo. A escola está organizada por uma estrutura pedagógica e também administrativa.

Entretanto, para este momento cabe pensar a escola, para algo que possa ultrapassar a estrutura organizacional, pois nesse interim a escola pulsa. Para auxiliar - ou não - nesse pulsar existe o currículo, lembrando que este, em alguns momentos, "[...] inibe, desestrutura, torna técnico o lugar da escola" (LIMA, 2010, p. 29). Torna-se necessário pensar a escola nesse misto, como lembra Lima (2010), ela dociliza e possibilita vida, disciplina e proporciona sonhos, ela forma e também cria projetos, ela ainda demarca territórios, mas ao mesmo tempo, sua intensidade, faz com que as margens desses territórios possam ser borradas.

Claro que não se pode deixar de compreender o tempo como elemento significativo para que todo o processo possa ser desenvolvido, pensado e até justificado. Ele é quem delimita e possibilita o acontecer da pulsação que envolve a escola. Pensando com Veiga e Fonseca (2012), esse tempo está relacionado em diversos movimentos: o calendário, dias letivos, feriados, datas de avaliação, períodos de reuniões, cursos, a saber, um tempo chronos. Por vezes, a escola, que deveria ser lugar do ótimo ócio, do tempo livre, de kairós, da possibilidade de pensar uma pedagogia pobre, acaba perdendo esse lugar.

Temos, portanto, o currículo e sua tentativa disciplinar e por outro lado todo o pulsar dentro da escola.

\begin{abstract}
A escola que nasce sob a perspectiva do discurso moderno - e que se ocupa de formar, disciplinar, docilizar os sujeitos - trama, ao mesmo tempo, em sua organização, em sua interioridade, possibilidades de vida, projetos e sonhos. Ao considerar as relações de poder produzidas no interior da escola, as práticas de coabitação de diferentes grupos sociais que não se situam simetricamente, estamos assumindo que, nas irregularidades, nas bordas de uma organização escolar, reside um cotidiano intenso, borbulhante, no interior do qual assistimos a diferentes práticas culturais que (des) organizam e (des) territorializam a escola (LIMA, 2010, p.28).
\end{abstract}

A escola vive esse entremeio, essa constante metamorfose: ser um espaço regrado, delimitado e restrito, mas ao mesmo tempo lugar de descobertas, possibilidades do novo. O lugar das normas e das transgressões. A escola então, seria esse lugar onde habitam as diferenças, nesse ponto percebese a abertura de uma pulsação - a escola - permeada de diversos outros ritmos, desejos, vontades - 
as crianças - como se o pulso da escola fosse o coração e as crianças, professores, funcionários fossem tudo aquilo que completa esse corpo, o qual necessita trabalhar em harmonia. Mas por vezes, o corpo fica doente, em outros momentos ele trabalha em seu funcionamento pleno e saudável. Saber lidar com as oscilações desse corpo parece ser necessário, saudável.

Ao pensar dessa forma, "A reorganização da escola deverá ser buscada de dentro para fora." (VEIGA; FONSECA, 2012, p. 33). Por isso, mais uma vez torna-se fundamental compreender o funcionamento dessa instituição - a escola -, pois somente assim conseguiremos mobilizar mudanças e criar novas possibilidades. As mudanças do mundo podem começar dentro dos muros dessa escola e aos poucos espalharem-se para fora desses muros, a alteridade volta a ser arma fundamental.

Ser criança é ir além, até mesmo daquilo que acreditamos ou estudamos sobre como ser criança. Permanecer desconfiando, descobrindo, reinventando, aquilo que já parece estar posto e estabelecido, certo e definido. "As crianças nos convidam - às vezes nos forçam - a nós, adultos, a nos tornarmos crianças. Teremos a coragem e o desprendimento necessário para isso?” (GALLO, 2010, p. 120). Ou ainda pode-se pensar: estamos atentos para esse convite? Percebemos que estamos sendo convocados? Ou as paixões já foram caladas, de tal forma, que não temos mais possibilidade de nos tornarmos inacabados?

Claro que se percebe algumas mudanças existentes na escola, afinal, "[...] mudanças têm sido, então, a burocratização do outro, sua inclusão curricular, seu dia no calendário, seu folclore, seu exotismo, sua pura biodiversidade" (SKLIAR, 2003, p. 197). Não estamos menosprezando, em hipótese alguma, essas necessidades, mas "[...] voltamos a recriar um (velho) discurso técnico, racional, vazio, sem relação com o outro. ” (SKLIAR, 2003, p. 198). Pensando ainda com Skliar (2003) precisamos de mais "representações como olhares", "metamorfose das identidades" e “vibração com o outro". Nessa direção:

[...] a escola é também o lugar da experiência, o lugar onde ensaiamos formas de estar-juntosuns-dos-outros, lugar onde desejamos, onde trocamos afetos, onde arriscamos, onde nos surpreendemos. Trata-se, enfim, de tomar a escola como espaço em que vibra intensamente a vida. (LIMA, 2010, p.33).

Sendo assim, a escola "acolhe todas as expressões de vida e reconhece que, no plano dessas diferenças, há uma multiplicidade de trocas, afetos, desejos e cuidado" (LIMA, 2010, p. 34). Entretanto, o que nós, como professores, estamos fazendo na escola? Alimentamos essas 
possibilidades ou simplesmente seguimos algo que é imposto? Possibilitamos as trocas, afetos, desejos e cuidados, ou apenas seguimos um currículo? O que nos cabe fazer? O que nos resta fazer?

Exercitemos a práxis interrogativa: “¿es possible en la espacialidad molar y concêntrica de la escuela promover otras potencias de vida infantil, otros movimientos y líneas en ese territorio tan maltratado, descuidado y desconsiderado?” (KOHAN, 2009, p. 30). Esse modelo de educação, que mais parece uma fábrica, pode ser alterado? ¿Puede ser la educación institucionalizada algo diferente de una fábrica y un auxiliar del reconocimiento? [...] ¿Es posible un acontecimiento, un devenir y otras potencias habiten la escuela?" (KOHAN, 2009, p. 31).

Entretanto e, talvez mais fundamental, a crítica de hoje, realmente é aquilo que significa, ou deveria significar "escola"? Do latim schola e da palavra grega skholé: "tempo livre, descanso, adiantamento, estudo, discussão, classe, escola, lugar de ensino" (MASSCHELEIN; SIMONS, 2015, p. 25). Critica-se um local que se dedica ao tempo livre, descanso, discussão?

Em grande medida a escola acaba sendo o local de civilização da criança e consequentemente das infâncias, onde as paixões perdem espaço e a racionalidade torna-se fundamental.

É preciso libertar a criança da "infância”, quero dizer, dessa situação de controle estrito e, a pretexto de amadurecimento, dessa interiorização das coações e dos comportamentos embrutecedores, em relação aos adultos, que lhe são incutidos pela pedagogia [...] (SCHÉRER, 2009, p. 35).

Vejamos, a escola não é um lugar em que se deve fazer qualquer coisa, mas ao mesmo tempo, não pode ser esse espaço que cala, amordaça, interrompe a infância. A escola tem papel fundamental para a criança e não apenas nesse sentido que percebemos na escola hoje - ou naquilo que se denomina de escola -, que ao entrar no primeiro ano, não raramente, a criança escuta: "agora acabou a brincadeira”. Nela há possibilidade de "[...] deixar o seu passado e os antecedentes familiares para trás [...] deixar pra lá todos os tipos de regras e expectativas sociológicas, econômicas e relacionadas à cultura" (MASSCHELEIN; SIMONS, 2015, p. 31 e 35).

“A escola não está separada da sociedade, mas é única, visto que é o local, por excelência, de suspensão escolástica e profanação pela qual o mundo é aberto" (MASSCHELEIN; SIMONS, 2015, p. 45). Compreende-se, portanto, por esse viés, que a escola tem um lugar OUTRO, uma possibilidade OUTRA, ela não é e não deve ser família, sociedade, economia, cultura, mas estaria inserida em outra lógica, seria e estaria em uma brecha, na possibilidade de um não lugar. A complexidade de tal raciocínio não é fácil, pois desconstrói tudo aquilo que vivemos como sendo escola e ao mesmo tempo 
precisa-se lidar com essa criança, que vive algo que também não é linear e determinado, a saber, a infância.

Deve-se compreender, como destacará Schérer (2009) o processo de civilização se dá pelo processo de pedagogização. Fala-se de um domínio que atua para a civilidade, que se dá pelo investimento da repressão das paixões e organização delas, como uma bússola para mostrar a direção. Tentemos pensar mais além, busquemos outras possibilidades, “[...] elementos que "fazem” a escola - suspensão, profanação, o mundo, atenção, disciplina, técnica - estão conectados (ou, certamente, podem ser conectados) com a experiência da habilidade [...] (MASSCHELEIN; SIMONS, 2015, p. 69). Essa escola que possa ter pedagogia relacionada com "fazer o tempo livre uma realidade" (MASSCHELEIN; SIMONS, 2015, p.97).

Um espaço para que a infância possa, realmente, ser valorizada. "A escola deveria estar mais atenta a deixar que a infância faça a si própria em vez de pretender fazer da infância algo predeterminada, diferente do que ela é” (KOHAN, 2010, p. 131). Uma escola OUTRA, talvez possa ser possível quando, em alguma medida, esquecermos, pois, "toda ação exige esquecimento, assim como toda vida orgânica exige não somente luz, mas também a escuridão" (NIETZSCHE, 2015, p. 50). Esquecer aquilo que acreditamos ser a escola. Esquecermos das famílias. Esquecermos da política. Esquecermos. Essa é uma pista para pensarmos em uma escola que possa gerar, também, felicidade, sendo que:

Aquele que não sabe instalar-se no limiar do instante, esquecendo todo o passado, aquele que não sabe, como uma deusa da vitória, colocar-se de pé uma vez sequer, sem medo e sem vertigem, este não saberá jamais o que é a felicidade, e o que é ainda pior: ele jamais estará em condições de tornar os outros felizes (NIETZSCHE, 2015, p.50)

Instalar-se no instante em um mundo insistentemente cronológico e acelerado, enfrentar os medos e a vertigem provocados, muitas vezes, ao estarmos na escola ou na sala de aula, são necessidades para nos superarmos e encontrarmos um pouco mais de felicidade em tudo aquilo que realizamos.

\section{SOPROS FINAIS: O PODER DO PENSAR}

Para a criança, a cor não se reduz a uma simples impressão visual, mas afeta todos os sentidos: ela a aspira, respira, escuta, sorve, degusta [...] (SCHÉRER, 2009, p.110). 
Espero aqui dar alguns sopros finais ao texto, mas, principalmente, possibilitar desconfortos, afim de que possamos continuar pensando aquilo que queremos e entendemos como criança, infância, filosofia, escola e consequentemente educação e formação.

A infância deve ser tratada em sua pluralidade, assim como nossa própria vida está repleta de plurais. Portanto, as infâncias nos dão uma lição de vida, elas nos mostram a real potencialidade de estar vivo, das descobertas, de uma nova-idade, do novo, do inacabamento, mas isso tudo cessa. O devir torna-se estagnado. Tornamo-nos adultos civilizados. Perde-se a possibilidade de continuar um devir. Estamos acabados. Acabados.

Discutimos aquilo que não somos mais e ao mesmo tempo não temos muitas outras saídas para voltar a ser, mas a busca parece ser por essa volta a algo que se perdeu, ou ainda deslocar-se, pois não há forma de voltar no tempo e não necessariamente precisamos voltar. A infância torna-se algo que foge da racionalidade e, por isso, torna-se tão complexo de escrever ou até mesmo dizer sobre. "Assim, a tarefa de escrever a infância extrapola o âmbito da língua, torna-se um ato político, uma manifestação política da igualdade e da diferença [...]” (KOHAN, 2010, p. 126). A política aqui, como destaca Kohan (2010), sendo possibilidade de pensar e também de viver com os outros.

Ao falarmos de infâncias, tratamos de um "não-lugar", o que exige cuidado, pois não se alcança dizer sobre o "não-lugar". Quando dizemos ele já deixa de ser um "não-lugar”, cria-se uma identidade, pois nomeia-se. Não se pode ser o "não-lugar", sendo ele o inteiramente outro, algo do qual quando dizemos estamos projetando muita idealização daquilo que gostaríamos de encontrar, mas se pode dizer indícios, podemos inventar sentidos a partir dos efeitos da experiência com o "nãolugar”. Quando nós, da educação, falamos dessas infâncias, sempre estaremos em falta. Sendo assim, as palavras são insuficientes. Sempre saberemos pouco.

Não somos preparados para falar dos inacabamentos. Tudo parece necessitar, exigir, obrigar uma certeza, exatidão. O incerto, o "não saber", parece tornar as coisas menores. A imprecisão acaba por tornar-se menos. Não obstante, os espaços para "devires" somem, sendo assim, parece que apagamos também espaços para as infâncias.

A escola que temos hoje, da forma que ela é, no modelo que ela acontece, não nos serve. Não estou aqui dizendo que ela não é necessária, ou ainda que devemos acabar com a escola, estou dizendo que na forma como ela vem sendo entendida e o jeito com que está trabalhando, não nos serve. Precisamos de uma escola outra, sendo que esse outro, na verdade, é aquilo que ela deveria ser. A escola de hoje esqueceu o que é ser escola, se é que em algum momento, se lembrou. 
A filosofia entra nesse caminho para potencializar as infâncias, pois se esta é múltipla, aquela também. A filosofia da infância nada mais é do que a possibilidade de acessar a fenda, ou pelo menos estarmos mais perto dela. E nesse momento você pode começar a se perguntar: mas como fazer isso?

Poderia responder: não estamos aqui descrevendo uma fórmula, mas tendo consciência que o pensar é, por si só, revolucionário, é um começo. Não digo que tal afirmação seja simples de compreender. O pensamento tem esse poder de mobilizar, desestruturar e consequentemente nos provocar e deslocar.

As intersecções que podem existir entre criança, infância e filosofia são ou podem ser favorecidas com a escola, no formato que temos hoje? Ao tentar responder a questão, outra indagação aparece: o que caracteriza uma educação com mais qualidade? Assim se faz o movimento proposto pelo pensamento, acabamos por não nos acomodar com a resposta dada e logo realizamos mais questionamentos.

Confesso que com a atual conjuntura vivida no Brasil, não sei sobre a real concretude dessa escola outra, mas sigo firme na possibilidade de acreditar - como Hannah Arendt (2003) já disse que a crise pode ser produtiva, pode ser a possibilidade de mudanças. Talvez consigamos possibilitar novidades, outros caminhos, outras formas, a escola outra. Sendo assim, seguimos nessas reflexões, acreditando que elas possam nos trazer o desconforto e possivelmente novas formas de existirmos.

Não podemos esquecer que todos esses elementos aqui discutidos, só podem ser pensados e organizados, a partir de um tempo. Pensar o tempo sempre se faz necessário, dessa forma, solicito espaço para uma reflexão um pouco mais poética.

\section{OS TEMPEROS DOS TEMPOS DA INFÂNCIA}

Ganhar tempo. Aproveitar tempo.

Perder tempo. Administrar o tempo.

Aproveitar o tempo. Perca tempo.

Administrar o tempo. Ganhe tempo.

Perceba o tempo. Perceber o tempo.

$$
\begin{aligned}
& \text { Khrónos - quantidade } \\
& \text { Kairós-oportunidade } \\
& \text { Aión-experiência }
\end{aligned}
$$


Quanto tempo tenho? Quantidade.

Quanto tempo falta? Oportunidade.

Qual é o seu tempo? Experiência.

Ontem o tempo passou!

Hoje o tempo passa!

Amanhã o tempo passará!

Tudo é tempo.

Nada tem tempo.

Somos nosso tempo de vida e o tempo que nos resta à vida.

Vivemos ou "tempemos"?

Você vive a sua vida ou apenas deixa o tempo vive-la?

Você vive a sua vida ou perde tempo com a vida dos outros?

Tempo relativo... Futuro.

Tempo passageiro... Passado.

Tempo presente!

Qual o tempo da infância? Aión.

Como a escola lida com o tempo? Khrónos.

Como são as crianças de cada tempo? Kairós.

Há um tempo filosófico que podemos pensar a filosofia da infância?

A infância preocupa-se com a filosofia?

E a filosofia pensa na infância?

Brinca e infância: "brincância"

Filosofia e infância: "filosofância"

Tempo e infância: "temperância”

A escola da infância: "escolância",

O tempo apressa momentos, pesa em excessos, represa possibilidades.

A infância, com leveza, desacelera e liberta. 
Devir, deve ir, deixar ir... De-vir.

E nós - adultos que esqueceram que foram crianças - interditamos: as brincadeiras, possibilidades, descobertas, pois já estamos na lógica; uma crono-lógica.

Tampe a temporalidade desse tempo tempestuoso, pois a temperatura depende dos temperos, das tentativas, de tu trazeres o tesão pela vida e o viver.

Tempere seu tempo...

Presenteie-se com seu tempo!

Permita os tempos das infâncias.

Que possamos dar voz e potência para aquilo que pensamos. Que a filosofia da infância se torne uma possibilidade para (re) pensarmos a escola outra, que possamos aprender mais com a infância, para que nos tornemos menos prontos a cada dia que passa, pois isso que poderia ser visto como uma involução, talvez possa ser a verdadeira revolução, não apenas na educação, mas para nós como seres humanos.

\section{REFERÊNCIAS:}

ARENDT, H. Entre o passado e o futuro. 5. ed. São Paulo: Perspectiva, 2003.

DELEUZE, G. Crítica e clínica. São Paulo: Editora 34, 1997.

GALLO, S. Infância e poder: algumas interrogações à escola. In: KOHAN, W. O. (Org.). Devir-criança da filosofia: infância da educação. Belo Horizonte: Autêntica, 2010.

KOHAN, W. O. Infancia y filosofía. Colección Pergunto, dialogo, aprendo. México: Editorial Progreso. 2009.

Vida e morte da infância, entre o humano e o inumano. In: Educação e Realidade. Porto Alegre, v. 35, n. 3, p. 125-138, set./dez., 2010. Disponível em: http://seer.ufrgs.br/educacaoerealidade/article/view/13083

LIMA, P. M. Cartografias, tempos e espaços da escola: linhas e fluxos de um (outro) desejo. In: MIGUEL, D. S.; LIMA, P. M. (Org.) Violências em (com) textos: olhares. Florianópolis: Ed. UDESC, 2010.

MASSCHELEIN, J. SIMONS, M. Em defesa da escola: uma questão pública. 2. ed. Belo Horizonte: Autêntica, 2015.

MASSCHELEIN, J. E-ducando o olhar: a necessidade de uma pedagogia pobre. Rio Grande do Sul: Educação \& Realidade, v. 33, n. 1, 2008.

MONTAIGNE, M. de. Os Ensaios: livro I. São Paulo: Nova Cultura, 1996.

NIETZSCHE, F. Escritos sobre história. Tradução: Noéli Correia de Melo. São Paulo: Folha de São Paulo, 2015.

SAVIANI, D. Projeto 20 anos do HISTED BR. As concepções pedagógicas na história da educação brasileira. 2005. (Encontro). Disponível em: http://www.histedbr.fe.unicamp.br/navegando/artigos_pdf/Dermeval_Saviani_artigo.pdf Acesso em: 04 de Set. 2017. 
SCHÉRER, R. Infantis: Charles Fourier e a infância para além das crianças. Belo Horizonte: Ed. Autêntica, 2009.

SKLIAR, C. Desobedecer a linguagem: Educar. São Paulo: Autêntica, 2014.

Pedagogia (improvável) da diferença: e se o outro não estivesse aí? São Paulo: DP\&A, 2003.

VEIGA, I. P. A; FONSECA, M. (Org.). As dimensões do projeto político-pedagógico: novos desafios para a escola. 9.

Ed. Campinas: Papirus, 2012.

\section{KAIRÓS: VALSAR COM A INFÂNCIA, NA ESCOLA, ATRAVÉS DA EXPERIÊNCIA FILOSÓFICA}

RESUMO

O presente texto disserta sobre a possibilidade de uma escola outra e, como base para isso, a discussão sobre a ideia de uma filosofia da infância. A base do trabalho apresentado - o qual tem como foco uma pesquisa bibliográfica - têm os autores: Walter Omar Kohan, Carlos Skliar, Rene Schérer e Jan Masschelein, auxiliares do valsar narrativo. Como objetivos pretende-se versar sobre infância, criança, escola, experiência e consequentemente pensar a formação para além de currículos e seguir na direção de uma possibilidade de viver a vida. Muito maior do que da possibilidade da resposta dada, o ponto central é realizar aberturas para perguntas, afinal não seria essa a melhor forma para que possamos estar sempre em um caminhar reflexivo e filosófico?

Palavras-chave: Filosofia da infância. Escola. Criança.

\section{KAIRÓS: WALTZ WITH THE CHILDHOOD, IN THE SCHOOL, THROUGH PHILOSOPHICAL EXPERIENCE} ABSTRACT

This paper discusses the possibility of school another and, in order to do so, also the discussion about the idea of a philosophy of the childhood. The basis of the work presented - which focuses on a bibliographical research - has the authors: Walter Omar Kohan, Carlos Skliar, Rene Schérer and Jan Masschelein, auxiliaries of the narrative waltz. The goals are to narrate the childhood, the children, the school, the experiences and, consequently, thinking about training beyond the curricula and moving towards a possibility to live life. Far bigger than the possibility of the given answers, the central point is to open up questions, after all, would not that be the best way for us to be always on a philosophical and reflective path?

Keywords: Philosophy of childhood. School. Child.

\section{KAIRÓS: VALSAR CON LA INFANCIA, EN LA ESCUELA, A TRAVÉS DE LA EXPERIENCIA FILOSÓFICA} RESUMEN

El presente texto diserta sobre la posibilidad de una escuela otra y, como base para ello, la discusión sobre la idea de una filosofía de la infancia. La base del trabajo presentado - el cual tiene como foco una investigación bibliográfica - tiene los autores: Walter Omar Kohan, Carlos Skliar, Rene Schérer y Jan Masschelein, auxiliares del valsar narrativo. Como objetivos se pretende versar sobre la infancia, los niños, la escuela, la experiencia y, consecuentemente, pensar la formación más allá de currículos y seguir en dirección a una posibilidad de vivir la vida. Mucho más que la posibilidad de la respuesta dada, el punto central es realizar aberturas para preguntas, al final, ¿no sería esa la mejor forma para que podamos estar siempre en un caminar reflexivo y filosófico?

Palabras clave: Filosofía de la infancia. Escuela. Niño. 